\title{
Engulfed by Glia: Glial Pruning in Development, Function, and Injury across Species
}

\author{
${ }^{\oplus}$ Stephan Raiders, ${ }^{1,2}$ Taeho Han, ${ }^{3}$ Nicole Scott-Hewitt, ${ }^{4,5}{ }^{\circledR}$ Sarah Kucenas, ${ }^{6}$ Deborah Lew, ${ }^{7}$ Mary A. Logan, \\ and ${ }^{(1)}$ Aakanksha Singhvi ${ }^{1,2}$ \\ ${ }^{1}$ Division of Basic Sciences, Fred Hutchinson Cancer Research Center, Seattle, Washington 98109, ${ }^{2}$ Molecular and Cellular Biology Graduate \\ Program, University of Washington, Seattle, Washington $98195,{ }^{3}$ UCSF Weill Institute for Neurosciences, University of California San Francisco, \\ San Francisco, California 94158, ${ }^{4}$ F.M. Kirby Center for Neurobiology, Boston Children's Hospital, Boston, Massachusetts 02115, ${ }^{5}$ Stanley Center for \\ Psychiatric Research, Broad Institute of Massachusetts Institute of Technology and Harvard, Cambridge, Massachusetts 02142, ${ }^{6}$ Department of \\ Biology, University of Virginia, Charlottesville, Virginia 22904, ${ }^{7}$ Department of Biological Sciences, Fordham University, Bronx, New York 10458, \\ and ${ }^{8}$ Jungers Center, Department of Neurology, Oregon Health and Science University, Portland, Oregon 97239
}

Phagocytic activity of glial cells is essential for proper nervous system sculpting, maintenance of circuitry, and long-term brain health. Glial engulfment of apoptotic cells and superfluous connections ensures that neuronal connections are appropriately refined, while clearance of damaged projections and neurotoxic proteins in the mature brain protects against inflammatory insults. Comparative work across species and cell types in recent years highlights the striking conservation of pathways that govern glial engulfment. Many signaling cascades used during developmental pruning are re-employed in the mature brain to "fine tune" synaptic architecture and even clear neuronal debris following traumatic events. Moreover, the neuronglia signaling events required to trigger and perform phagocytic responses are impressively conserved between invertebrates and vertebrates. This review offers a compare-and-contrast portrayal of recent findings that underscore the value of investigating glial engulfment mechanisms in a wide range of species and contexts.

Key words: glia; phagocytosis; neuronal pruning; model organisms

\section{Introduction}

The nervous system contains two major cell types, glia and neurons. Glia likely evolved with sense-organ formation, cephalization, and development of interneuron-enriched circuits (Verkhratsky and Butt, 2013). Glia:neuron ratios track with neural function complexity, with the human brain containing roughly equal numbers of neurons and glia (Goodman et al., 2009; Herculano-Houzel, 2014; von Bartheld et al., 2016). Glia closely associate with neurons, reciprocally monitoring and responding to altered activity (Hidalgo et al., 2011; Corty and Freeman, 2013; Allen and Eroglu, 2017). Indeed, glia-neuron interactions are absolutely critical for nervous system development and functions.

Received June 30, 2020; revised 0ct. 20, 2020; accepted 0ct. 26, 2020.

This work was supported by National Institute of Health T32T32AG066574 to SR (AS laboratory); Glenn Foundation for Medical Research and AFAR Junior Faculty Grant, Simons Foundation/SFARI Grant 488574, National Institute of Health R01 NS114222, and Anderson Foundation and the Marco J. Heidner Foundation Pilot Fund to A.S.; National Institutes of Health R21 NS107771, National Institutes of Health R01 NS117934, and Ken and Ginger Harrison Term Professor Award to M.A.L.; National Institutes of Health R01-EY026215 and Sigma-Xi grants in aid to D.L. (Silvia Finnemann laboratory); Pew Charitable Trusts, National Institute of Mental Health R01MH119349, and Burroughs Welcome Fund to T.H. (Anna Molofsky laboratory); National Institutes of Health-T32: Training in Molecular Neurodegeneration to N.S.-H. (Beth Stevens laboratory); and University of Virginia Brain Institute and National Institutes of Health R01 NS072212 to S.K. We apologize to those whose work was not cited, due to either space constraints or our oversight.

The authors declare no competing financial interests.

Correspondence should be addressed to Aakanksha Singhvi at asinghvi@fredhutch.org.

https://doi.org/10.1523/JNEUROSCI.1660-20.2020

Copyright $\odot 2021$ the authors
One mechanism by which glia modulate neural development, homeostasis, and circuit function is by engulfing degenerating neurons, projections, and synaptic material (Schafer and Stevens, 2013; Wilton et al., 2019). This has been observed across species (Drosophila, mouse, human, zebrafish) in both the CNS and PNS. Glial engulfment of neuron fragments eliminates exuberant projections in development and removes synapses that fail to adequately mature. Since synaptic plasticity and structural refinement are thought to be the cellular basis of learning and memory (Nimchinsky et al., 2002; Segal, 2005; Calabrese et al., 2006; Harms and Dunaevsky, 2007), glial engulfment in fully developed animals presumably also has profound impacts on cognitive function. In both the CNS and PNS of adult animals, multiple glia types across various species clear degenerating neural debris after injury (Freeman, 2015; Vilalta and Brown, 2018; Wilton et al., 2019). Given these roles, it is not surprising that defective glial engulfment is implicated in various neurologic disorders of development (e.g., autism), function (sensory/cognitive impairment), and aging (e.g., Alzheimer's disease, Parkinson's disease) (Nedergaard and Verkhratsky, 2012; Chung et al., 2015). However, almost 200 years after being discovered by Dutrochet (1824), the regulatory logic by which glia regulate engulfment of neuron fragments remains poorly defined at molecular resolution.

Numerous in vitro and in vivo models ranging from Caenorhabditis elegans to mammals are being used to explore glial phagocytic activity, and there are striking molecular similarities across these systems and species. This alludes to deep evolutionary conservation, and perhaps origins, of this critical glial 
Table 1. Glia engulf neurons and neural fragments in several contexts ${ }^{a}$

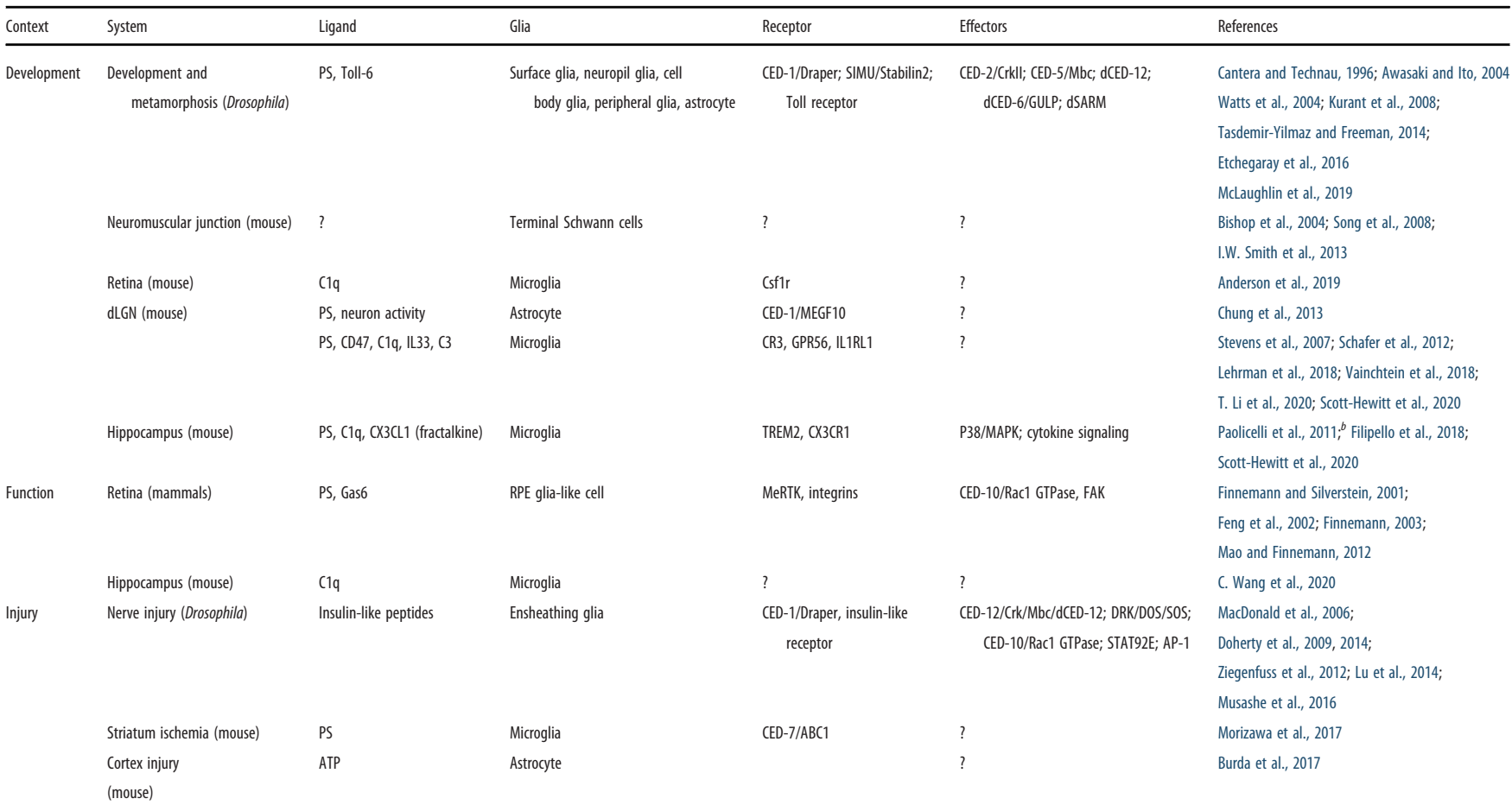

a Work in multiple systems highlights relevant molecules and mechanisms by which glia engulf in development, neural function, and following injury (summarized here).
${ }^{b}$ Fractalkine signaling; also, other brain regions not listed.

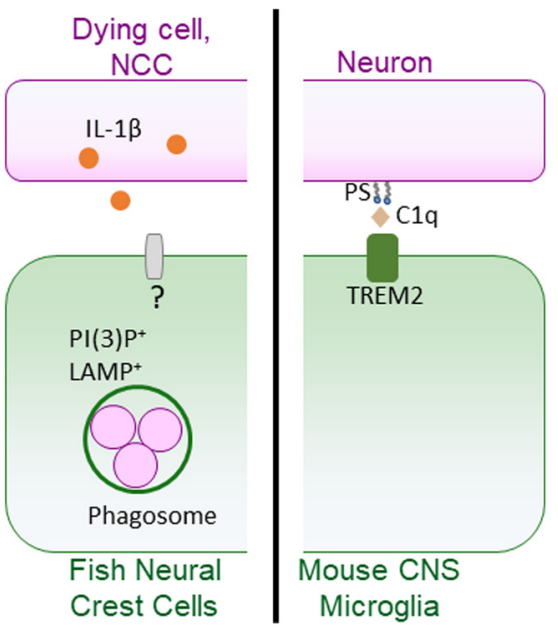

Figure 1. Recent insights into glial engulfment across species in the contexts of development. In zebrafish, IL-1 $\beta$ triggers neural crest cells to phagocytose neuron debris during development. Microglia in the mouse CNS recognize PS as an "eat me" signal to initiate phagocytosis through the opsonin C $1 q$ and likely various receptors, including TREM2. Top, Magenta represents cellular source of ligand. Bottom, Green represents engulfing cell. ?, Indirect evidence.

function. Briefly, as summarized in Table 1 and Figure 1, two well-established "eat me" signals that mark neuron fragments for engulfment by glial cells are phosphatidylserine (PS) and secreted complement proteins. This is true for both synaptic fragments of living neurons and dying cells. PS is recognized by one of a handful of known or putative PS receptors, including CED-1/MEGF10/Draper1/Jedi1, MerTK, CED-7/ $\mathrm{ABC}$ transporter and integrins. Some of this recognition is mediated by cognate bridging molecules, such as Gas6 and MFGE8, which act at the intercellular interface and facilitate binding of PS to PS receptors. Secreted complement factors, such as $\mathrm{C} 1 \mathrm{q}$ and $\mathrm{C} 3$, which are recognized by cognate complement receptors on various glial subtypes, also serve as tags to promote phagocytic clearance (Luchena et al., 2018). Finally, while studies indicate that additional receptors may be at play, these await identification. Downstream effectors include components of the machinery that transmits phagocytosis signals (Mao and Finnemann, 2012; Ziegenfuss et al., 2012; Tasdemir-Yilmaz and Freeman, 2014; Morizawa et al., 2017). This includes the small GTPase Rac1/CED-10, which is known to mediate cytoskeletal remodeling; the phagocytosis adapter PTB domain containing protein CED-6/dCED-6/ GULP1; and the signaling adapter proteins CED-2/CrkII and CED-12/dCED-12/ELMO1.

A comprehensive discussion of glial engulfment is beyond the scope of this minireview. Instead, we highlight recent advances identifying novel cell-biological contexts and mediators of glial phagocytosis in development (zebrafish neural crest cells), function (C. elegans sense-organ glia), brain health (interleukins, PS recognition), and disease (microglia in retinitis pigmentosa [RP] progression) (Fig. 1). We note that, in addition to engulfment by glia, synaptic elimination can occur through cell-intrinsic mechanisms and other signaling cues (semaphorins, ephrins, C1qI1/ Bai3). We refer readers to a number of excellent in-depth reviews for both of these topics (Schafer and Stevens, 2013; Freeman, 2015; Riccomagno and Kolodkin, 2015; Neniskyte and Gross, 2017; Luchena et al., 2018; Wilton et al., 2019).

\section{Glial engulfment in development}

During development, proper shaping of the CNS and PNS is necessary to form a functional and adaptable organism. But development is not simply a generative process. It also includes a significant sculpting component, which is thought to properly tune the system for efficiency and plasticity. Therefore, it is not unexpected that neuronal death and degeneration are prevalent 
during development and are important for the removal of excess cells, refining neuronal connectivity, and editing developmental errors that may stochastically arise, to enable optimal nervous system functions (Arya and White, 2015).

In the CNS, mesodermal lineage microglia participate in developmental synaptic pruning of several brain regions. Notably, pruning by microglia is not restricted to engulfment of neurites and synapses: recent work in zebrafish indicates that microglia also engulf myelin sheaths of oligodendrocytes during development (Hughes and Appel, 2020). Moreover, phagocytic sculpting of retinal structure also involves glial-glial engulfment interactions involving microglia. In the postnatal mouse, subsets of retinal astrocytes undergo cell death and are cleared by local microglia to ensure proper vascular development and function in the mature eye (Puñal et al., 2019). The underlying neuronal cues that specify which synapses are to be eliminated remain largely unknown.

Several receptors and secreted factors in microglia, including CR3/Mac1, TREM2, GPR56, P2yR12, Cx3Cr1, and complement proteins mediate developmental synaptic pruning across multiple regions (Paolicelli et al., 2011; Schafer et al., 2012; Sipe et al., 2016; Filipello et al., 2018; T. Li et al., 2020). For example, in the visual system, complement factors $\mathrm{C} 1 \mathrm{q}$ and $\mathrm{C} 3$ contribute to synaptic removal by microglia in a CR3-dependent manner (Stevens et al., 2007; Schafer et al., 2012; Vasek et al., 2016). Complementindependent microglial synaptic elimination has been demonstrated in the hippocampus (Paolicelli et al., 2011; Weinhard et al., 2018) and barrel cortex (Gunner et al., 2019). Further, the TAM (Tyro/Axl/Mer receptor tyrosine kinase family) receptor MerTK is expressed in microglia and regulates its phagocytosis of apoptotic cells in adult mouse neurogenic regions and neurodegeneration models (Fourgeaud et al., 2016). It remains unclear whether these pathways are temporally or spatially regulated during developmental pruning, and whether these mechanisms mediate function independently or cooperatively. Readers are referred to comprehensive reviews on these topics (Stephan et al., 2012; Schafer and Stevens, 2015; Luchena et al., 2018; Wilton et al., 2019).

Ectodermal lineage-derived astrocyte glia of the CNS also contribute to remodeling of immature neuronal circuitry. The first description of this was in the dLGN, the key thalamic relay nucleus of the visual system (Chung et al., 2013). Astrocytes remove weak synapses that fail to stabilize using the receptors CED-1/Draper1/MEGF10 and MerTK (Chung et al., 2013). Intriguingly, loss of the TREM2 receptor in microglia causes aberrantly increased astrocytic pruning activity, beyond what might be expected for mere compensatory changes (Jay et al., 2019). Further, in the developing mouse dLGN, ablating MerTK causes a transient increase in microglial engulfment, indicating a possible compensatory mechanism for impaired astrocyte engulfment (Chung et al., 2013). These studies suggest that astrocytes and microglia may cooperate for efficient developmental pruning, but how astrocytes regulate engulfment or coordinate with microglia remains poorly defined.

In the PNS, terminal Schwann cell glia at the developing neuromuscular junction clear shed axosome debris (small vesicles released from axons) and remove supernumerary synapses (Bishop et al., 2004; I. W. Smith et al., 2013; Darabid et al., 2014; Lee et al., 2016). This engulfment correlates with neuronal activity, since weaker neuromuscular junction terminals are preferentially eliminated. Although the mechanisms underlying this process and its relationship to neuronal activity are not well defined, they include roles for the glial isoform of Neurofascin
(Nfasc155) and neuregulin Type III (NRG1 Type III) on motor axon nerve terminals (Roche et al., 2014; Lee et al., 2016). Roles for engulfment by other peripheral glia in sculpting sensory cell/ neuron number or shape during development have not yet been reported.

The importance of glia-dependent phagocytosis and pruning of neural fragments during early development is uncontested. However, our understanding of the cellular and molecular mechanisms that mediate these glial functions remains superficial. Two insights into developmental pruning are summarized as follows (Fig. 1): (1) identification of a new cell type phagocytosing dying neuron debris in the developing zebrafish (Zhu et al., 2019); and (2) establishment of PS exposure as an "eat me" signal for microglial pruning in development (Scott-Hewitt et al., 2020).

Migratory neural crest cells phagocytose dead cells in the developing nervous system

Cell death is an important component of development, and it produces substantial amounts of debris that must be cleared. Currently, the mechanisms responsible for clearing this debris remain poorly understood. For example, neural tube closure generates a significant amount of cellular debris during early neurogenesis (Schluter, 1973; Weil et al., 1997; Buss et al., 2006). This debris is efficiently cleared, although myeloid-derived phagocytes have not yet colonized the trunk (Herbomel et al., 1999). Using in vivo, time-lapse imaging in zebrafish, we discovered that neural crest cells are phagocytic during early development (Zhu et al., 2019). We showed that these cells migrate toward dead cells using recruitment mechanisms (e.g., IL-1 $\beta$ ) similar to those used by professional phagocytes, and they process engulfed material, such as other phagocytes via $\mathrm{PI}(3) \mathrm{P}^{+}$and Lamp $1^{+}$phagosomes (Zhu et al., 2019). Intriguingly, we observed that crest cells even migrate into the ventral spinal cord via transition zones and phagocytose debris in the CNS (something we observed when studying glial dynamics at these locations, but did not understand) (C. J. Smith et al., 2016). Together, our findings reveal a novel role for neural crest cells in debris clearance in the CNS and PNS during early development, before the infiltration of professional phagocytes. This new role of neural crest cells during early neural development places them among a growing list of nonprofessional phagocytes, including glia in the embryonic Drosophila CNS, zebrafish epithelial cells, PNS satellite glia, retinal cells, and neuronal progenitors, that function when professional phagocytes are not present or sufficient to clear debris. This reveals a broader context in which the immune system interacts with the nervous system; and many questions remain, including how the nonprofessional and professional phagocytes interact during these early stages just after myeloid cell infiltration, and how debris clearance is coordinated when professional and nonprofessional phagocytes coexist.

Coupling early circuit development with specific genetic manipulations, imaging tools, and behavioral assays will provide insight into the roles that neural crest cells play as phagocytes and molecular mechanisms that drive both professional and nonprofessional phagocytes during neural development. This will lead to a deeper understanding of fundamental processes that build the nervous system and provide insight into what could also go awry in neurodevelopmental disorders.

The role of PS in microglial pruning of synaptic elements The signals specifying which neuronal structures (e.g., axons, synaptic boutons, and postsynaptic elements) are targeted 
for elimination by microglia, and how these signals may be regulated, remain largely unknown. Although the secreted complement proteins $\mathrm{C} 1 \mathrm{q}$ and $\mathrm{C} 3$ label a subset of retinogeniculate synapses in the $\mathrm{dLGN}$, the molecules that recruit complement and microglia to specific axons and synaptic elements remain elusive. Similarly, although the role of neuronal activity in synaptic refinement (Katz and Shatz, 1996; Hua and Smith, 2004; Hooks and Chen, 2006; Huberman, 2007; Burbridge et al., 2014) and microglial-mediated synaptic pruning has also been well established (Schafer et al., 2012; Sipe et al., 2016), how activity is translated into local downstream cues mediating engulfment is not well understood.

Several immune signals contribute to the regulation of synaptic pruning by microglia. For example, neuronal CD47, a wellknown "don't eat me" signal, regulates microglial pruning in an activity-driven manner through interaction with the microglial receptor, SIRP $\alpha$. CD47-null mice exhibit enhanced synaptic engulfment, synapse elimination, and fewer synapses in adulthood (Lehrman et al., 2018). Moreover, loss of CD47 occurs on less-active retinal inputs in vivo, suggesting a model in which "eat me" signals, such as C1q, localize to weak synapses, whereas "don't eat me" signals, such as CD47, are lost from weak synapses (Lehrman et al., 2018). What upstream neuronal signals initiate this process, and do various developing regions have common signals that can be recognized by a variety of microglial receptors and secreted proteins?

One immune molecule that regulates phagocytosis in diverse contexts is the phospholipid PS. Externalization of PS is one of the first events detected in cells undergoing apoptosis, contributing to recognition and removal by phagocytes. Transient, localized PS exposure events can also occur in a nonapoptotic manner, facilitating removal of specific subcellular structures by phagocytes (Smrz et al., 2007; Segawa et al., 2011). In neurons, PS exposure can occur locally on injured axons (ShachamSilverberg et al., 2018) or dendrites (Sapar et al., 2018), which are then targeted for elimination while the remaining uninjured cell structures are spared. Further, microglia express several known PS-binding receptors that have been implicated in microglial targeting and elimination: TREM2, GPR56, and TAM surface receptor tyrosine kinase proteins (which bind PS through adapter proteins, e.g., Gas6 and protein S) TYRO3, AXL, and Mer (Brown and Neher, 2014; Filipello et al., 2018; Lemke, 2019; T. Li et al., 2020). C1q can also bind to exposed PS (either directly or indirectly) and mediate engulfment (Païdassi et al., 2008; Martin et al., 2012). Indeed, a recent study demonstrated that exposed PS was sometimes present ex vivo on isolated synaptosomes that were also tagged with C1q (Györffy et al., 2018).

We have recently shown that synaptic PS exposure occurs predominantly at presynaptic terminals in both the hippocampus and the dLGN. We also found that microglia engulf PS-labeled material in a temporally regulated manner, coinciding with established periods of microglial pruning. Importantly, local developmental PS exposure occurs independently of caspase 3-mediated activation and apoptosis (Scott-Hewitt et al., 2020). Furthermore, in $\mathrm{C} 1 \mathrm{q} \mathrm{KO}$ animals, which have altered synaptic refinement and elimination in the visual thalamus (Stevens et al., 2007), we observed increases in PS-labeled presynaptic terminals, as well as a decrease in microglial engulfment of PS-labeled material (Scott-Hewitt et al., 2020). Together, these findings suggest that locally exposed PS could be a common neuronal signal during developmental pruning, one that may be recognized by several glial-expressed receptors and secreted factors. How these pathways cooperate, in a temporally or spatially specific manner, and whether PS exposure contributes to microglial synaptic targeting in disease, will be important to examine in the future.

\section{Glial engulfment in neural function}

Whereas the importance of glial engulfment in the context of development and injury is well established, the role of glial phagocytic function in mature neural function remains less clear. Understanding how glia shape circuit function and activity requires robust models to reliably monitor significant changes in neuronal connectivity and signaling.

In the CNS, one established context for glial engulfment in healthy neural tissue after development is the vertebrate retina, where RPE glia-like cells engulf fragments of photoreceptor outer segments (Bairati and Orzalesi, 1963; Young, 1967; Young and Bok, 1969). This enables renewal and turnover of the outer segments, thereby presumably maintaining retinal health in the face of continued phototoxic damage. Perturbations of this process correlate with loss in visual acuity and retinal degeneration (Kevany and Palczewski, 2010; Lakkaraju et al., 2020).

A more recently discovered site of glial engulfment in the healthy, mature CNS is the hippocampus. For example, microglial phagocytosis of synapses between engram cells has recently been shown to mediate forgetting in healthy hippocampi of adult mice through the C1q pathway (C. Wang et al., 2020). It is also suggested that synapse engulfment by astrocytes via ephrin receptors may affect hippocampal contextual fear memory (Koeppen et al., 2018). Mechanisms underlying these glial functions are not well established, however. Notably, new insights into engulfment in the mature brain extend to neural progenitor cells. Recent work reveals that neural progenitor cells may share signaling mechanisms with glia (e.g., ATP signaling) to phagocytose apoptotic neurons during adult neurogenesis ( $\mathrm{Lu}$ et al., 2011; Leeson et al., 2018).

In the PNS, there is significant turnover and neurogenesis in the adult enteric nervous system. Resultant dying neuron debris is phagocytosed by the intestinal tissue-resident macrophages called muscularis macrophages (Kulkarni et al., 2017). Engulfment functions in other PNS glia have not yet been described.

Below, we present two unpublished findings showing that glial engulfment also dynamically modulates normal sensory perception in the C. elegans PNS and basal excitability in the mouse CNS (Fig. 2). These studies also extend the role of glial engulfment from the CNS (retinal pigment epithelial [RPE], astrocytes, microglia) to the peripheral nervous system sense-organ glia.

\section{C. elegans glia dynamically tune engulfment of neuron endings to modulate animal behavior}

The C. elegans nervous system comprises 302 neurons and 56 glia. Glial subtypes in this animal model include astrocyte-like glia that enwrap the brain neuropil and synapses, mesodermallineage glia, and peripheral sense-organ glia that associate with cognate sensory neurons (Singhvi and Shaham, 2019). Three features make studies of glial functions and glia-neuron interactions exquisitely precise in C. elegans. (1) all neurons and glia in this animal make invariant contacts within a mapped connectome. This structurally invariant, but behaviorally plastic, neural network drives behaviors, such as sensation, sleep, mating, locomotion, and memory. (2) C. elegans is optically transparent, facilitating in vivo microscopy and optogenetics. Last, its extensive molecular-genetic toolkit allows any glia or neuron of choice to be individually and reproducibly manipulated. Effects of such perturbation can be queried at multiple 


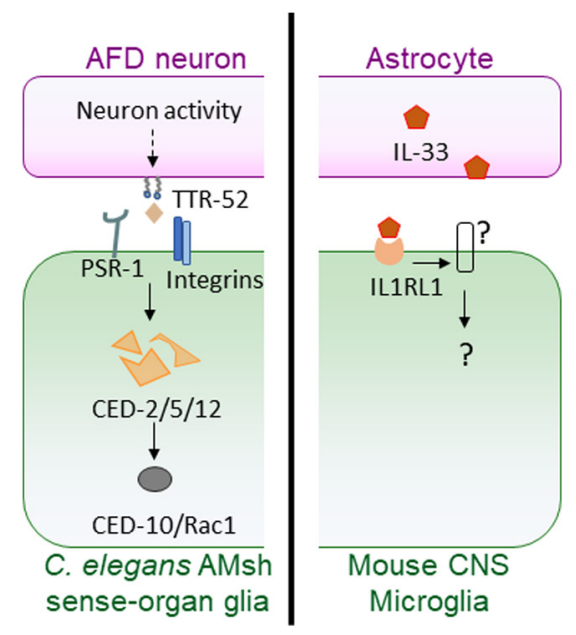

Figure 2. Recent insights into glial engulfment across species in the contexts of function. In C. elegans sense-organ, glia dynamically engulf fragments of an associated neuron ending by repurposing components of the phagocytosis machinery. In the mouse thalamus, microglia engulf neuron fragments using IL-33 ligand and IL1RL1 receptor signaling. For color code, see Figure 1. ?, Indirect evidence.

levels, from genetic and genomic analyses, to cell-biological and functional imaging of neural circuit networks, to animal behavior and memory assays.

Recent studies of single glia-neuron interactions by us and others have shown that C. elegans glia share molecular and functional characteristics with glia in other species (Singhvi and Shaham, 2019), including regulation of neuron shape and functions. For instance, the largest $C$. elegans sense organ is the amphid, which comprises 12 sensory neurons mediating perception of different modalities, and two glia, including the amphid sheath glia cell (AMsh glia). The AMsh glia associates with all 12 neurons, including the AFD neuron, the animal's primary thermosensory neuron (Hedgecock and Russell, 1975; Perkins et al., 1986; Mori and Ohshima, 1995; Inada et al., 2006). Sensory neurons, such as the AFD, must carefully regulate the morphology of their specialized sensory endings to properly track and encode environmental information. We and others have shown that AMsh glia secrete molecular cues to regulate the shape and functions of the AFD neuron, including the ionic milieu around AFD-neuron endings (Bacaj et al., 2008; Singhvi et al., 2016; Wallace et al., 2016; Yoshida et al., 2016). All AMsh molecular cues described thus far through these studies are conserved, expressed in mammalian glia, and disease-relevant.

Strikingly, glial engulfment had not been described in this animal model. In monitoring AMsh glia-AFD contact zones in vivo using transgenically labeled animals, we serendipitously observed labeled AFD puncta that were discontinuous with the AFD cell body and within AMsh glia. Subsequent validation studies confirmed that these puncta indeed reflect fragments of AFD ending engulfed by the AMsh glia (Raiders et al., 2020). Thus, engulfment is another glial function conserved in C. elegans. This finding also identifies thermosensation as a sensory modality, in addition to mammalian vision, where glial engulfment has been documented in healthy tissue.

We find that AMsh glial engulfment occurs only in postdevelopmental adult animals. Remarkably, similar to developmental pruning by astrocytes and microglia, AMsh glial engulfment tracks AFD neuron activity and the "eat me" signal, PS. In line with this, we uncovered a role for components of the conserved apoptotic phagocytosis machinery of $C$. elegans (Mangahas and
Zhou, 2005; X. Wang and Yang, 2016) also in AMsh glial engulfment of AFD endings. Some of these proteins are orthologs of molecules previously implicated in glial engulfment in Drosophila (CED-12/ELMO, CED-10/Rac1 GTPase) and mammalian retina (Rac1 GTPase) (Kevany and Palczewski, 2010; Freeman, 2015) (Table 1). In addition, we uncovered two novel mediators for glial engulfment, including a PS receptor and a regulator of PS exposure (Raiders et al., 2020). These findings underscore the analogous molecular mechanisms of glial engulfment across species (C. elegans to human), systems (CNS/PNS), and context (development, injury, function), and they highlight the speed and precision this experimental setting affords.

Importantly, our ability to probe glial engulfment with singlecell precision in vivo revealed two fundamental attributes of this process: (1) C. elegans AMsh glia actively drive the extent of engulfment rather than passively clear shed neuron debris; and (2) AMsh glia-regulated engulfment dynamically modifies AFD neuron shape and tunes thermotaxis behavior of adult animals (Raiders et al., 2020). Together, these studies provide an explicit demonstration that engulfment of a single neuron by a single glia directly modulates neuron shape and animal behavior. Whether dynamic glial engulfment similarly tunes sensorineural functions and animal behavior in other animal models will be fascinating to explore.

CNS-derived interleukin-33 promotes activity-dependent microglial synapse engulfment and restricts seizure susceptibility

Innate immune signaling regulates tissue development and homeostasis, including the remodeling of neuronal synapses in the CNS. Immune dysfunction is implicated in the pathogenesis of neurodevelopmental disorders, including epilepsy (Ravizza et al., 2006; Aronica et al., 2007; Vezzani et al., 2015), a predisposition for episodes of hypersynchronous neuronal activity, or seizures (Scharfman, 2007; Jiruska et al., 2010). Because microglia are the dominant immune cells in the brain parenchyma, they are a potential mechanistic link between immune activation and epilepsy (Eyo et al., 2017; X. Zhao et al., 2018). Therefore, defining molecular regulators of microglial-synapse interactions is a topic of emerging interest.

Microglia engulf synapses during development (Stevens et al., 2007; Paolicelli et al., 2011; Schafer et al., 2012; Vainchtein et al., 2018) and can also promote synapse formation during adult learning (Parkhurst et al., 2013; Miyamoto et al., 2016). Microglia contact neuronal dendritic spines in an activity-dependent manner (Wake et al., 2009; Tremblay et al., 2010; Y. Li et al., 2012; Eyo et al., 2014, 2015; Madry et al., 2018), indicating that they are directly or indirectly responsive to neuronal activity. Although microglial identity depends partly on lineage-determining transcription factors, such as PU.1, microglial function is shaped by an exquisite sensitivity to environmental cues, such as TGF- $\beta$, that can rapidly alter microglial identity in response to injury, pathology, or neuronal activity (Butovsky et al., 2014; Gosselin et al., 2014,2017; Lavin et al., 2014; Hrvatin et al., 2018). However, the link between microglial transcriptional responses to immune signaling and their functional outputs, such as engulfment, is not well described.

The IL-1 family member interleukin-33 (IL-33) is a novel regulator of microglial synapse remodeling during development and in adult plasticity (Vainchtein et al., 2018; Nguyen et al., 2020), and it also plays important protective roles in the context of neurodegeneration and after injury (Gadani et al., 2015; Pomeshchik et al., 2015; Fu et al., 2016; Lau et al., 2020). Microglia respond to IL-33 via the obligate coreceptor Il1rl1, and global deletion of 
Il33 or Il1rl1 during development causes defective microglial engulfment of excitatory synapses and circuit hyperexcitability (Vainchtein et al., 2018). One of the first brain regions to express IL-33 is the thalamus, where expression begins around postnatal day 5 (Vainchtein et al., 2018), and increases as synapses mature (Golshani et al., 1998; Yoshida et al., 2009; Takeuchi et al., 2014, 2017). Notably, the thalamus is a key relay station of the brain, and hyperactivity of the reciprocal connections between thalamus and cortex is a well-described circuit that can drive seizures (Blumenfeld, 2005; Paz et al., 2010, 2013; Makinson et al., 2017).

In recent work, we define the impact of IL-33 on the microglial epigenomic and transcriptomic landscape and identify the scavenger receptor MARCO and neuronal activity as two factors that modulate IL-33-dependent microglial engulfment. We further demonstrate that IL-33 is required to regulate excitatory and inhibitory synapse numbers during postnatal development and restrict seizure susceptibility by early adulthood. These data reveal an integral role for IL-33-dependent microglial activation in orchestrating excitatory/inhibitory synaptic balance and in regulating seizure susceptibility during brain development.

\section{Glial engulfment in injury}

Across species, many classes of glia display enhanced phagocytic activity in response to acute injury, as well as chronic neurodegenerative conditions. For example, in the inner ear of chick and mouse, glial-like support cells phagocytose hair cell debris when they become damaged (Wan et al., 2013; Monzack et al., 2015). In the brain, phagocytic activity of activated microglia and astrocytes has been well documented following traumatic injury, stroke, and in various disease states (Neher et al., 2012; Verkhratsky et al., 2016; Tremblay et al., 2019; Wilton et al., 2019; Hilu-Dadia and Kurant, 2020). These engulfment responses are often neuroprotective, clearing antigenic cell fragments and toxic protein aggregates (e.g., amyloid- $\beta$ ) from the CNS. Interestingly, astrocyte-microglia interactions can also occur in injury states. For example, in some contexts, activated microglia secrete factors, including C1q, IL1, and TNF $\alpha$, to inhibit phagocytic activity of astrocytes (Liddelow et al., 2017). Finally, broad inflammation in the CNS results in microglial engulfment of astrocytic end feet at the blood-brain barrier, which promotes dysfunctional cerebral vasculature (Haruwaka et al., 2019).

Peripheral Schwann cells also clear debris after acute and chronic insults. Schwann cells remove myelin following sciatic nerve injury through autophagy and the TAM receptors Axl and MertK (Brosius Lutz et al., 2017), and also phagocytose peripheral nerve terminals in a mouse model of motor axon neuropathy (Cunningham et al., 2020). Mechanisms driving this engulfment are not well elucidated. Whether myelinating oligodendrocyte glia in the CNS clear debris after injury also remains unclear.

Below is a summary of recent studies describing examples of both protective and disease promoting roles for glia in various model systems (Fig. 3).

\section{Glial phagocytic responses to neural injury in Drosophila}

The adult fruit fly (Drosophila melanogaster) offers a convenient, genetically tractable, in vivo system to investigate pathways that govern glial phagocytic reactions to neurodegeneration. In flies, the transmembrane receptor Draper is essential for glial clearance of degenerating neuronal projections during developmental pruning and after acute nerve injury (MacDonald et al., 2006; Ziegenfuss et al., 2012; Lu et al., 2014; Tasdemir-Yilmaz and Freeman, 2014). The related mammalian receptors (MEGF10/

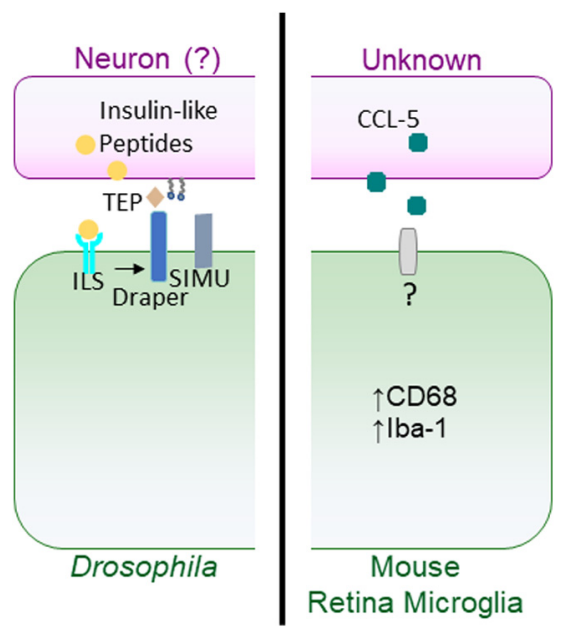

Figure 3. Recent insights into glial engulfment across species in the context of injury/disease. In Drosophila, nerve injury induces release of insulin-like peptides and the complement-like thioester factors (TEPs). Insulin signaling drives engulfment of neuron debris through CED-1/Draper upregulation. In the retina of a RP mouse model, the proinflammatory cytokine CCL5 is upregulated and microglia exhibit elevated CD68 and Iba1, suggestive of an activated state that exacerbates neuron loss. For color code, see Figure 1. ?, Indirect evidence.

Jedi) are also essential for proper glial sculpting of the forming CNS (Wu et al., 2009; Chung et al., 2013). In addition, the family of Draper/MEGF10 receptors tap into common intracellular transduction cascades, including Src tyrosine kinases, Jun kinases, and cytoskeletal remodelers (e.g., Racl GTPase) (Doherty et al., 2009; Ziegenfuss et al., 2012; Lu et al., 2014; Logan, 2017; Purice et al., 2017; Winfree et al., 2017).

One pressing question in the field of glial immunity is related to activation of glial engulfment responses. How do injured (or apoptotic) neurons signal to glial cells to elicit protective immune responses, including clearance of neural debris? Recent work in the adult fly now reveals that acute nerve injury triggers insulin-like signaling cascades in responding glial cells (specifically, ensheathing glia) and, subsequently, upregulation of the Draper receptor (Musashe et al., 2016). Activation of glial insulin-like signaling likely occurs through calcium-dependent release of insulin-like peptide ligands from severed axons (Musashe et al., 2016). In mammals, activation of insulin-like signaling in the brain is indeed neuroprotective in acute injury and disease models, although the specific effects of insulin/IGF signaling on glial engulfment function, and specifically expression of MEGF10, remains to be determined. Notably, during Drosophila development, apoptotic neurons promote Draper upregulation in local cortex glial cells through an alternative mechanism. Specifically, dying neurons release ligands to activate glial Toll-like receptors, which, in turn, upregulate Draper transcription in a FoxO-dependent manner (McLaughlin et al., 2019). Together, these studies reveal that a variety of conserved signaling cascades orchestrate glial phagocytic function in the fly by converging on the Draper/MEGF10 engulfment pathway.

As described above, dying neurons (or degenerating neuronal fragments) often present the inner membrane leaflet phospholipid PS to tag themselves for phagocytic removal. Indeed, this process can be observed and manipulated in both the developing and adult CNS of the fly (Hakim-Mishnaevski et al., 2019; HiluDadia and Kurant, 2020), and recent work suggests that abnormal expression of the glial engulfment receptors Draper or six 
microns under (SIMU) can trigger degeneration of select mature neurons, promoting PS presentation, and subsequent clearance (Hilu-Dadia and Kurant, 2020). How glial cells nonautonomously promote stress and, ultimately death, of discrete neuronal subtypes remains to be determined.

Finally, it now clear that secreted complement proteins (e.g., C1q/C3) also mark select neurites and synapses for removal by glial cells (Schafer and Stevens, 2015). Although flies lack an adaptive immune system, they do possess several genes that encode secreted complement-like factors, namely, thioester-containing proteins (TEPs), which similarly coat invading pathogens and apoptotic cells to be recognized by phagocytes. Interestingly, recent work indicates that at least one secreted TEP serves as a ligand for the Draper receptor in the developing salivary gland (Lin et al., 2017). Moreover, our laboratory has shown that TEPs are transcriptionally upregulated in phagocytic glia in response to acute nerve injury and required for proper glial clearance of degenerating axons (Purice et al., 2017; Boisvert and M.L., unpublished data). Together, these findings further highlight the conservation of extrinsic and intrinsic glial signaling pathways to maintain optimal brain function, health, and synaptic architecture.

\section{Microglial pruning in $R P$}

Microglia are the resident macrophages and primary defenders of the neural retina. In a healthy retina, resting microglia are localized in the inner layer, among retinal interneurons and retinal ganglion cells, the output cells of the retina. Upon infection or in response to cell injury, retinal microglia become activated and migrate to the site of injury to protect the retina reducing inflammation and thus retinal degeneration by phagocytosing foreign bodies and/or cellular debris (Silverman and Wong, 2018). However, in chronic damage, such as in inherited retinal degenerations, microglia may either protect the retina (Silverman et al., 2019) or aggravate the degenerative process (L. Zhao et al., 2015; C. Wang et al., 2020). Knowing the either protective or aggravating role of microglia for each disease is an important step toward providing treatment. One of the most important group of inherited retinal degenerations, characterized by death of photoreceptors, is called RP. RP usually progresses slowly with loss of night vision followed by progressive loss of daylight vision in middle age (Ferrari et al., 2011). While inactivation of microglia in a specific type of RP has been shown to delay retinal degeneration (Eyo et al., 2014), their involvement in all the different types of RP is still to be determined. The role of microglia in RP because of mutation in the gene encoding the receptor tyrosine kinase Mer (MerTK) is still unclear. MerTK dysfunction causes an unusually severe form of RP in human patients with blindness in teenage years (Mackay et al., 2010). MerTK-dependent RP (mutMerTK RP) mutant mice (Nandrot et al., 2000; Duncan et al., 2003) lack MerTK activity and mimic the symptoms of human RP with rapid postnatal retinal degeneration and apoptosis of rod photoreceptors by postnatal day (PN) 25 (Dowling and Sidman, 1962; Mazzoni et al., 2019). Rod dysfunction and death in mutMerTK RP are not rod cell autonomous because MerTK is not expressed by rods. Instead, it serves as an engulfment receptor for neighboring RPE cells during daily clearance of spent rod outer segment debris as part of a lifelong maintenance program of outer segment renewal. Distress of rods is thus secondary to failure of debris clearance by mutMerTK RPE cells. This does not explain, however, the fast rate of progression of mutMerTK RP, which is especially intriguing because outer segment renewal commences in mice/rats only after eye opening (around PN 16). Not surprisingly, in advanced stage of the disease, abnormal presence of activated microglia in the photoreceptor layer of mutMerTK retina is found and has been thought to clear cellular debris (Thanos, 1992; Kohno et al., 2015; Di Pierdomenico et al., 2017). While these data support a role for microglia in the severity of mutMerTK RP, depletion of microglia in rats presenting a natural deletion for MerTK gene (RCS rats) from PN 15 show no benefit to photoreceptors and actually worsen visual function (He et al., 2019). However, most recently, the Finnemann laboratory found activated microglia in the photoreceptor layer of the RCS rat retina as early as PN 20, an age before detectable outer segment debris buildup, let alone photoreceptor apoptosis (Lew et al., 2020), suggesting a role for microglia in addition to the late-stage clearance of cellular debris. Moreover, the proinflammatory cytokine CCL5, known to be a chemoattractant for microglia, is elevated as early as PN 14 in RCS rat retina. Strikingly, PN 14 RCS retina also show elevated levels of microglia proteins Iba-1 and CD68, indicating microglia activation before migration and, remarkably, before eye opening, at which age outer segment renewal becomes fully active. Several strategies to reduce microglia starting at PN 10 were effective in slowing the rate of photoreceptor loss and partly preserving rod function (Lew et al., 2020). Notably, these approaches included applying tamoxifen nonsystemically, as eye drops. These recent advances by the Finnemann laboratory reveal that microglia in mutMerTK RP play roles unrelated and before clearance of dying rods or their debris, which accelerate the rate of retinal degeneration. The specific nature and cell type of origin of the stimuli that activate microglia remain to be identified. It is tempting to speculate that modulating such stimuli (e.g., by decreasing activation before onset of symptoms) in inherited mutMerTK RP might extend useful vision to human patients with mutMerTK RP.

In conclusion, insights into the critical glial function of phagocytosis are rapidly evolving. Advent of new molecular genetic technologies has provided power and renewed excitement in investigating the active role of glia in modulating neural functions, including through engulfment. Yet, it is clear that many fundamental attributes of glial engulfment remain unexplored at the level of molecular mechanism and single-cell resolution. New signaling effectors will undoubtedly continue to be discovered, but, more importantly, the developmental and functional consequences of glial engulfment programs need to be further elucidated.

Nonetheless, it is already apparent that mechanisms of glial engulfment are broadly conserved across systems, contexts, and species, suggesting that molecular insight from facile genetic models will facilitate rapid dissection of how phagocytic activity of glia contributes to formation, function, and disease of the nervous system. For example, microglial synaptic targeting not only occurs in development, but also in vulnerable brain regions of several disease models (Neher et al., 2012; Y. Wang et al., 2015; Hong et al., 2016; Schafer et al., 2016; Vasek et al., 2016; Werneburg et al., 2020).

The explosion of developmental genetic systems examining glial engulfment of neuron fragments is providing rapid insights into how neuronal activity directs innate glial responses, engulfment, and, ultimately, mature circuitry. An important area where many pressing questions remain is how glial phagocytic responses subtly influence developed brain circuits. This is especially relevant because even fine modulations of synaptic connectivity alter learning and memory, sleep patterns, circadian rhythms, and susceptibility to disease. Finally, there are important outstanding questions 
to explore regarding aged brain function and neurodegenerative disorders. In what contexts are glial phagocytic responses beneficial, and in which instances are they detrimental? As we move forward, continued comparative analyses of glial engulfment across species and systems (central and peripheral glia) will offer exciting new opportunities to understand nervous system formation and homeostasis.

\section{References}

Allen NJ, Eroglu C (2017) Cell biology of astrocyte-synapse interactions. Neuron 96:697-708.

Anderson SR, Roberts JM, Zhang J, Steele MR, Romero CO, Bosco A, Vetter ML (2019) Developmental Apoptosis Promotes a Disease-Related Gene Signature and Independence from CSF1R Signaling in Retinal Microglia. Cell Rep 27:2002-2013.e5.

Aronica E, Boer K, van Vliet EA, Redeker S, Baayen JC, Spliet WG, van Rijen PC, Troost D, da Silva FH, Wadman WJ, Gorter JA (2007) Complement activation in experimental and human temporal lobe epilepsy. Neurobiol Dis 26:497-511.

Arya R, White K (2015) Cell death in development: signaling pathways and core mechanisms. Semin Cell Dev Biol 39:12-19.

Awasaki T, Ito K (2004) Engulfing action of glial cells is required for programmed axon pruning during Drosophila metamorphosis. Curr Biol 14:668-677.

Bacaj T, Tevlin M, Lu Y, Shaham S (2008) Glia are essential for sensory organ function in C. elegans. Science 322:744-747.

Bairati A, Orzalesi N (1963) The ultrastructure of the pigment epithelium and of the photoreceptor-pigment epithelium junction in the human retina. J Ultrastruct Res 9:484-496.

Bishop DL, Misgeld T, Walsh MK, Gan WB, Lichtman JW (2004) Axon branch removal at developing synapses by axosome shedding. Neuron 44:651-661.

Blumenfeld H (2005) Cellular and network mechanisms of genetically-determined absence seizures. Epilepsia 3:181-203.

Brosius Lutz A, Chung WS, Sloan SA, Carson GA, Zhou L, Lovelett E, Posada S, Zuchero JB, Barres BA (2017) Schwann cells use TAM receptor-mediated phagocytosis in addition to autophagy to clear myelin in a mouse model of nerve injury. Proc Natl Acad Sci USA 114:E8072-E8080.

Brown GC, Neher JJ (2014) Microglial phagocytosis of live neurons. Nat Rev Neurosci 15:209-216.

Burbridge TJ, Xu HP, Ackman JB, Ge X, Zhang Y, Ye MJ, Zhou ZJ, Xu J, Contractor A, Crair MC (2014) Visual circuit development requires patterned activity mediated by retinal acetylcholine receptors. Neuron 84:1049-1064.

Burda JE, Sofroniew MV (2017) Seducing astrocytes to the dark side. Cell Res 27:726-727.

Buss RR, Sun W, Oppenheim RW (2006) Adaptive roles of programmed cell death during nervous system development. Annu Rev Neurosci 29:1-35.

Butovsky O, Jedrychowski MP, Moore CS, Cialic R, Lanser AJ, Gabriely G, Koeglsperger T, Dake B, Wu PM, Doykan CE, Fanek Z, Liu L, Chen Z, Rothstein JD, Ransohoff RM, Gygi SP, Antel JP, Weiner HL (2014) Identification of a unique TGF- $\beta$-dependent molecular and functional signature in microglia. Nat Neurosci 17:131-143.

Calabrese B, Wilson MS, Halpain S (2006) Development and regulation of dendritic spine synapses. Physiology (Bethesda) 21:38-47.

Cantera R, Technau GM (1996) Glial cells phagocytose neuronal debris during the metamorphosis of the central nervous system in Drosophila melanogaster. Dev Genes Evol 206:277-280.

Chung WS, Clarke LE, Wang GX, Stafford BK, Sher A, Chakraborty C, Joung J, Foo LC, Thompson A, Chen C, Smith SJ, Barres BA (2013) Astrocytes mediate synapse elimination through MEGF10 and MERTK pathways. Nature 504:394-400.

Chung WS, Welsh CA, Barres BA, Stevens B (2015) Do glia drive synaptic and cognitive impairment in disease? Nat Neurosci 18:1539-1545.

Corty MM, Freeman MR (2013) Cell biology in neuroscience: architects in neural circuit design: glia control neuron numbers and connectivity. J Cell Biol 203:395-405.

Cunningham ME, Meehan GR, Robinson S, Yao D, McGonigal R, Willison HJ (2020) Perisynaptic Schwann cells phagocytose nerve terminal debris in a mouse model of Guillain-Barré syndrome. J Peripher Nerv Syst 25:143-151.
Darabid H, Perez-Gonzalez AP, Robitaille R (2014) Neuromuscular synaptogenesis: coordinating partners with multiple functions. Nat Rev Neurosci 15:703-718.

Di Pierdomenico J, García-Ayuso D, Pinilla I, Cuenca N, Vidal-Sanz M, Agudo-Barriuso M, Villegas-Pérez MP (2017) Early events in retinal degeneration caused by rhodopsin mutation or pigment epithelium malfunction: differences and similarities. Front Neuroanat 11:14

Doherty J, Logan MA, Taş demir OE, Freeman MR (2009) Ensheathing glia function as phagocytes in the adult Drosophila brain. J Neurosci 29:47684781.

Doherty J, Sheehan AE, Bradshaw R, Fox AN, Lu TY, Freeman MR (2014) PI3K signaling and Stat92E converge to modulate glial responsiveness to axonal injury. PLoS Biol 12:e1001985.

Dowling JE, Sidman RL (1962) Inherited retinal dystrophy in the rat. J Cell Biol 14:73-109.

Duncan JL, LaVail MM, Yasumura D, Matthes MT, Yang H, Trautmann N, Chappelow AV, Feng W, Earp HS, Matsushima GK, Vollrath D (2003) An RCS-like retinal dystrophy phenotype in MerKnockout mice. Invest Ophthalmol Vis Sci 44:826.

Etchegaray JI, Elguero EJ, Tran JA, Sinatra V, Feany MB, McCall K (2016) Defective Phagocytic Corpse Processing Results in Neurodegeneration and Can Be Rescued by TORC1 Activation. J Neurosci 36:3170-3183.

Eyo UB, Peng J, Swiatkowski P, Mukherjee A, Bispo A, Wu LJ (2014) Neuronal hyperactivity recruits microglial processes via neuronal NMDA receptors and microglial P2Y12 receptors after status epilepticus. J Neurosci 34:10528-10540.

Eyo UB, Gu N, De S, Dong H, Richardson JR, Wu LJ (2015) Modulation of microglial process convergence toward neuronal dendrites by extracellular calcium. J Neurosci 35:2417-2422.

Eyo UB, Murugan M, Wu LJ (2017) Microglia-neuron communication in epilepsy. Glia 65:5-18.

Feng W, Yasumura D, Matthes MT, LaVail MM, Vollrath D (2002) Mertk triggers uptake of photoreceptor outer segments during phagocytosis by cultured retinal pigment epithelial cells. J Biol Chem 277:17016-17022.

Ferrari S, Iorio ED, Barbaro V, Ponzin D, Sorrentino FS, Parmeggiani F (2011) Retinitis pigmentosa: genes and disease mechanisms. Curr Genomics 12:238-249.

Filipello F, Morini R, Corradini I, Zerbi V, Canzi A, Michalski B, Erreni M, Markicevic M, Starvaggi-Cucuzza C, Otero K, Piccio L, Cignarella F, Perrucci F, Tamborini M, Genua M, Rajendran L, Menna E, Vetrano S, Fahnestock M, Paolicelli RC, et al. (2018) The microglial innate immune receptor TREM2 is required for synapse elimination and normal brain connectivity. Immunity 48:979-991.e978.

Finnemann SC (2003) Focal adhesion kinase signaling promotes phagocytosis of integrin-bound photoreceptors. Embo J 22:4143-4154.

Finnemann SC, Silverstein RL (2001) Differential roles of CD36 and alphavbeta 5 integrin in photoreceptor phagocytosis by the retinal pigment epithelium. J Exp Med 194:1289-1298.

Fourgeaud L, Traves PG, Tufail Y, Leal-Bailey H, Lew ED, Burrola PG, Callaway P, Zagorska A, Rothlin CV, Nimmerjahn A, Lemke G (2016) TAM receptors regulate multiple features of microglial physiology. Nature 532:240-244.

Freeman MR (2015) Drosophila central nervous system glia. Cold Spring Harb Perspect Biol 7:a020552.

Fu AK, Hung KW, Yuen MY, Zhou X, Mak DS, Chan IC, Cheung TH, Zhang B, Fu WY, Liew FY, Ip NY (2016) IL-33 ameliorates Alzheimer's disease-like pathology and cognitive decline. Proc Natl Acad Sci USA 113:E2705-E2713.

Gadani SP, Walsh JT, Smirnov I, Zheng J, Kipnis J (2015) The glia-derived alarmin IL-33 orchestrates the immune response and promotes recovery following CNS injury. Neuron 85:703-709.

Golshani P, Warren RA, Jones EG (1998) Progression of change in NMDA, non-NMDA, and metabotropic glutamate receptor function at the developing corticothalamic synapse. J Neurophysiol 80:143-154.

Goodman M, Sterner KN, Islam M, Uddin M, Sherwood CC, Hof PR, Hou ZC, Lipovich L, Jia H, Grossman LI, Wildman DE (2009) Phylogenomic analyses reveal convergent patterns of adaptive evolution in elephant and human ancestries. Proc Natl Acad Sci USA 106:20824-20829.

Gosselin D, Link VM, Romanoski CE, Fonseca GJ, Eichenfield DZ, Spann NJ, Stender JD, Chun HB, Garner H, Geissmann F, Glass CK (2014) Environment drives selection and function of enhancers controlling tissue-specific macrophage identities. Cell 159:1327-1340. 
Gosselin D, Skola D, Coufal NG, Holtman IR, Schlachetzki JC, Sajti E, Jaeger BN, O’Connor C, Fitzpatrick C, Pasillas MP, Pena M, Adair A, Gonda DD, Levy ML, Ransohoff RM, Gage FH, Glass CK (2017) An environment-dependent transcriptional network specifies human microglia identity. Science 356:eaal3222.

Gunner G, Cheadle L, Johnson KM, Ayata P, Badimon A, Mondo E, Nagy MA, Liu L, Bemiller SM, Kim KW, Lira SA, Lamb BT, Tapper AR, Ransohoff RM, Greenberg ME, Schaefer A, Schafer DP (2019) Sensory lesioning induces microglial synapse elimination via ADAM10 and fractalkine signaling. Nat Neurosci 22:1075-1088.

Györffy BA, Kun J, Török G, Bulyáki É, Borhegyi Z, Gulyássy P, Kis V, Szocsics P, Micsonai A, Matkó J, Drahos L, Juhász G, Kékesi KA, Kardos J (2018) Local apoptotic-like mechanisms underlie complement-mediated synaptic pruning. Proc Natl Acad Sci USA 115:6303-6308.

Hakim-Mishnaevski K, Flint-Brodsly N, Shklyar B, Levy-Adam F, Kurant E (2019) Glial phagocytic receptors promote neuronal loss in adult Drosophila brain. Cell Rep 29:1438-1448.e1433.

Harms KJ, Dunaevsky A (2007) Dendritic spine plasticity: looking beyond development. Brain Res 1184:65-71.

Haruwaka K, Ikegami A, Tachibana Y, Ohno N, Konishi H, Hashimoto A, Matsumoto M, Kato D, Ono R, Kiyama H, Moorhouse A, Nabekura J, Wake H (2019) Dual microglia effects on blood brain barrier permeability induced by systemic inflammation. Nat Commun 10:5816.

He J, Zhao C, Dai J, Weng CH, Bian BS, Gong Y, Ge L, Fang Y, Liu H, Xu H, Yin ZQ (2019) Microglia mediate synaptic material clearance at the early stage of rats with retinitis pigmentosa. Front Immunol 10:912.

Hedgecock EM, Russell RL (1975) Normal and mutant thermotaxis in the nematode Caenorhabditis elegans. Proc Natl Acad Sci USA 72:40614065.

Herbomel P, Thisse B, Thisse C (1999) Ontogeny and behaviour of early macrophages in the zebrafish embryo. Development 126:3735-3745.

Herculano-Houzel S (2014) The glia/neuron ratio: how it varies uniformly across brain structures and species and what that means for brain physiology and evolution. Glia 62:1377-1391.

Hidalgo A, Kato K, Sutcliffe B, McIlroy G, Bishop S, Alahmed S (2011) Trophic neuron-glia interactions and cell number adjustments in the fruit fly. Glia 59:1296-1303.

Hilu-Dadia R, Kurant E (2020) Glial phagocytosis in developing and mature Drosophila CNS: tight regulation for a healthy brain. Curr Opin Immunol 62:62-68.

Hong S, Beja-Glasser VF, Nfonoyim BM, Frouin A, Li S, Ramakrishnan S, Merry KM, Shi Q, Rosenthal A, Barres BA, Lemere CA, Selkoe DJ, Stevens B (2016) Complement and microglia mediate early synapse loss in Alzheimer mouse models. Science 352:712-716.

Hooks BM, Chen C (2006) Distinct roles for spontaneous and visual activity in remodeling of the retinogeniculate synapse. Neuron 52:281-291.

Hrvatin S, Hochbaum DR, Nagy MA, Cicconet M, Robertson K, Cheadle L, Zilionis R, Ratner A, Borges-Monroy R, Klein AM, Sabatini BL, Greenberg ME (2018) Single-cell analysis of experience-dependent transcriptomic states in the mouse visual cortex. Nat Neurosci 21:120-129.

Hua JY, Smith SJ (2004) Neural activity and the dynamics of central nervous system development. Nat Neurosci 7:327-332.

Huberman AD (2007) Mechanisms of eye-specific visual circuit development. Curr Opin Neurobiol 17:73-80.

Hughes AN, Appel B (2020) Microglia phagocytose myelin sheaths to modify developmental myelination. Nat Neurosci 23:1055-1066.

Inada H, Ito H, Satterlee J, Sengupta P, Matsumoto K, Mori I (2006) Identification of guanylyl cyclases that function in thermosensory neurons of Caenorhabditis elegans. Genetics 172:2239-2252.

Jay TR, von Saucken VE, Munoz B, Codocedo JF, Atwood BK, Lamb BT, Landreth GE (2019) TREM2 is required for microglial instruction of astrocytic synaptic engulfment in neurodevelopment. Glia 67:1873-1892.

Jiruska P, Csicsvari J, Powell AD, Fox JE, Chang WC, Vreugdenhil M, Li X, Palus M, Bujan AF, Dearden RW, Jefferys JG (2010) High-frequency network activity, global increase in neuronal activity, and synchrony expansion precede epileptic seizures in vitro. J Neurosci 30:5690-5701.

Katz LC, Shatz CJ (1996) Synaptic activity and the construction of cortical circuits. Science 274:1133-1138.

Kevany BM, Palczewski K (2010) Phagocytosis of retinal rod and cone photoreceptors. Physiology (Bethesda) 25:8-15.

Koeppen J, Nguyen AQ, Nikolakopoulou AM, Garcia M, Hanna S, Woodruff S, Figueroa Z, Obenaus A, Ethell IM (2018) Functional consequences of synapse remodeling following astrocyte-specific regulation of Ephrin-B1 in the adult hippocampus. J Neurosci 38:5710-5726.

Kohno H, Koso H, Okano K, Sundermeier TR, Saito S, Watanabe S, Tsuneoka H, Sakai T (2015) Expression pattern of Ccr2 and Cx3cr1 in inherited retinal degeneration. J Neuroinflammation 12:188.

Kulkarni S, Micci MA, Leser J, Shin C, Tang SC, Fu YY, Liu L, Li Q, Saha M, Li C, Enikolopov G, Becker L, Rakhilin N, Anderson M, Shen X, Dong X, Butte MJ, Song H, Southard-Smith EM, Kapur RP, et al. (2017) Adult enteric nervous system in health is maintained by a dynamic balance between neuronal apoptosis and neurogenesis. Proc Natl Acad Sci USA 114:E3709-E3718.

Kurant E, Axelrod S, Leaman D, Gaul U (2008) Six-microns-under acts upstream of Draper in the glial phagocytosis of apoptotic neurons. Cell 133:498-509.

Lakkaraju A, Umapathy A, Tan LX, Daniele L, Philp NJ, Boesze-Battaglia K, Williams DS (2020) The cell biology of the retinal pigment epithelium. Prog Retin Eye Res 78:100846.

Lau SF, Chen C, Fu WY, Qu JY, Cheung TH, Fu AK, Ip NY (2020) IL-33PU.1 transcriptome reprogramming drives functional state transition and clearance activity of microglia in Alzheimer's disease. Cell Rep 31:107530.

Lavin Y, Winter D, Blecher-Gonen R, David E, Keren-Shaul H, Merad M, Jung S, Amit I (2014) Tissue-resident macrophage enhancer landscapes are shaped by the local microenvironment. Cell 159:1312-1326.

Lee YI, Li Y, Mikesh M, Smith I, Nave KA, Schwab MH, Thompson WJ (2016) Neuregulin1 displayed on motor axons regulates terminal Schwann cell-mediated synapse elimination at developing neuromuscular junctions. Proc Natl Acad Sci USA 113:E479-4E487.

Leeson H, Kasherman M, Chan-Ling T, Lovelace M, Brownlie J, Toppinen K, Gu B, Weible M (2018) P2X7 receptors regulate phagocytosis and proliferation in adult hippocampal and SVZ neural progenitor cells: implications for inflammation in neurogenesis. Stem Cells 36:1764-1777.

Lehrman EK, Wilton DK, Litvina EY, Welsh CA, Chang ST, Frouin A, Walker AJ, Heller MD, Umemori H, Chen C, Stevens B (2018) CD47 protects synapses from excess microglia-mediated pruning during development. Neuron 100:120-134.e126.

Lemke G (2019) How macrophages deal with death. Nat Rev Immunol 19:539-549.

Lew DS, Mazzoni F, Finnemann SC (2020) Microglia inhibition delays retinal degeneration due to MerTK phagocytosis receptor deficiency. Front Immunol 11:1463.

Li T, Chiou B, Gilman CK, Luo R, Koshi T, Yu D, Oak HC, Giera S, Johnson-Venkatesh E, Muthukumar AK, Stevens B, Umemori H, Piao X (2020) A splicing isoform of GPR56 mediates microglial synaptic refinement via phosphatidylserine binding. EMBO J 39:e104136.

Li Y, Du XF, Liu CS, Wen ZL, Du JL (2012) Reciprocal regulation between resting microglial dynamics and neuronal activity in vivo. Dev Cell 23:1189-1202.

Lin L, Rodrigues F, Kary C, Contet A, Logan M, Baxter R, Wood W, Baehrecke E (2017) Complement-related regulates autophagy in neighboring cells. Cell 170:158-171.e158.

Logan M (2017) Glial contributions to neuronal health and disease: new insights from Drosophila. Curr Opin Neurobiol 47:162-167.

Lu T, Doherty J, Freeman M (2014) DRK/DOS/SOS converge with Crk/ $\mathrm{Mbc} / \mathrm{dCed}-12$ to activate Rac1 during glial engulfment of axonal debris. Proc Natl Acad Sci USA 111:12544-12549.

Lu Z, Elliott M, Chen Y, Walsh J, Klibanov A, Ravichandran K, Kipnis J (2011) Phagocytic activity of neuronal progenitors regulates adult neurogenesis. Nat Cell Biol 13:1076-1083.

Luchena C, Zuazo-Ibarra J, Alberdi E, Matute C, Capetillo-Zarate E (2018) Contribution of neurons and glial cells to complement-mediated synapse removal during development, aging and in Alzheimer's disease. Mediators Inflamm 2018:1-12.

MacDonald J, Beach M, Porpiglia E, Sheehan A, Watts R, Freeman M (2006) The Drosophila cell corpse engulfment receptor Draper mediates glial clearance of severed axons. Neuron 50:869-881.

Mackay DS, Henderson RH, Sergouniotis PI, Li Z, Moradi P, Holder GE, Waseem N, Bhattacharya SS, Aldahmesh MA, Alkuraya FS, Meyer B, Webster AR, Moore AT (2010) Novel mutations in MERTK associated with childhood onset rod-cone dystrophy. Mol Vis 16:369-377.

Madry C, Kyrargyri V, Arancibia-Cárcamo IL, Jolivet R, Kohsaka S, Bryan RM, Attwell D (2018) Microglial ramification, surveillance, and 
interleukin- $1 \beta$ release are regulated by the two-pore domain $\mathrm{K}(+)$ channel THIK-1. Neuron 97:299-312.e296.

Makinson CD, Tanaka BS, Sorokin JM, Wong JC, Christian CA, Goldin AL, Escayg A, Huguenard JR (2017) Regulation of thalamic and cortical network synchrony by Scn8a. Neuron 93:1165-1179. e1166.

Mangahas PM, Zhou Z (2005) Clearance of apoptotic cells in Caenorhabditis elegans. Semin Cell Dev Biol 16:295-306.

Mao Y, Finnemann SC (2012) Essential diurnal Racl activation during retinal phagocytosis requires alphavbeta5 integrin but not tyrosine kinases focal adhesion kinase or Mer tyrosine kinase. Mol Biol Cell 23:11041114.

Martin M, Leffler J, Blom AM (2012) Annexin A2 and A5 serve as new ligands for C1q on apoptotic cells. J Biol Chem 287:33733-33744.

Mazzoni F, Müller C, DeAssis J, Lew D, Leevy WM, Finnemann SC (2019) Non-invasive in vivo fluorescence imaging of apoptotic retinal photoreceptors. Sci Rep 9:1590.

McLaughlin CN, Perry-Richardson JJ, Coutinho-Budd JC, Broihier HT (2019) Dying neurons utilize innate immune signaling to prime glia for phagocytosis during development. Dev Cell 48:506-522.e6.

Miyamoto A, Wake H, Ishikawa AW, Eto K, Shibata K, Murakoshi H, Koizumi S, Moorhouse AJ, Yoshimura Y, Nabekura J (2016) Microglia contact induces synapse formation in developing somatosensory cortex. Nat Commun 7:12540-12512.

Monzack EL, May LA, Roy S, Gale JE, Cunningham LL (2015) Live imaging the phagocytic activity of inner ear supporting cells in response to hair cell death. Cell Death Differ 22:1995-2005.

Mori I, Ohshima Y (1995) Neural regulation of thermotaxis in Caenorhabditis elegans. Nature 376:344-348.

Morizawa YM, Hirayama Y, Ohno N, Shibata S, Shigetomi E, Sui Y, Nabekura J, Sato K, Okajima F, Takebayashi H, Okano H, Koizumi S (2017) Reactive astrocytes function as phagocytes after brain ischemia via ABCA1-mediated pathway. Nat Commun 8:28.

Musashe D, Purice M, Speese S, Doherty J, Logan M (2016) Insulin-like signaling promotes glial phagocytic clearance of degenerating axons through regulation of Draper. Cell Rep 16:1838-1850.

Nandrot E, Dufour EM, Provost AC, Péquignot MO, Bonnel S, Gogat K, Marchant D, Rouillac C, Sépulchre de Condé B, Bihoreau MT, Shaver C, Dufier JL, Marsac C, Lathrop M, Menasche M, Abitbol MM (2000) Homozygous deletion in the coding sequence of the c-mer gene in RCS rats unravels general mechanisms of physiological cell adhesion and apoptosis. Neurobiol Dis 7:586-599.

Nedergaard M, Verkhratsky A (2012) Artifact versus reality: how astrocytes contribute to synaptic events. Glia 60:1013-1023.

Neher JJ, Neniskyte U, Brown GC (2012) Primary phagocytosis of neurons by inflamed microglia: potential roles in neurodegeneration. Front Pharmacol 3:27.

Neniskyte U, Gross CT (2017) Errant gardeners: glial-cell-dependent synaptic pruning and neurodevelopmental disorders. Nat Rev Neurosci 18:658-670.

Nguyen PT, Dorman LC, Pan S, Vainchtein ID, Han RT, Nakao-Inoue H, Taloma SE, Barron JJ, Molofsky AB, Kheirbek MA, Molofsky AV (2020) Microglial remodeling of the extracellular matrix promotes synapse plasticity. Cell 182:388-403.e15.

Nimchinsky EA, Sabatini BL, Svoboda K (2002) Structure and function of dendritic spines. Annu Rev Physiol 64:313-353.

Païdassi H, Tacnet-Delorme P, Garlatti V, Darnault C, Ghebrehiwet B, Gaboriaud C, Arlaud GJ, Frachet P (2008) C1q binds phosphatidylserine and likely acts as a multiligand-bridging molecule in apoptotic cell recognition. J Immunol 180:2329-2338.

Paolicelli RC, Bolasco G, Pagani F, Maggi L, Scianni M, Panzanelli P, Giustetto M, Ferreira TA, Guiducci E, Dumas L, Ragozzino D, Gross CT (2011) Synaptic pruning by microglia is necessary for normal brain development. Science 333:1456-1458.

Parkhurst CN, Yang G, Ninan I, Savas JN, Yates JR 3rd, Lafaille JJ, Hempstead BL, Littman DR, Gan WB (2013) Microglia promote learning-dependent synapse formation through brain-derived neurotrophic factor. Cell 155:1596-1609.

Paz JT, Christian CA, Parada I, Prince DA, Huguenard JR (2010) Focal cortical infarcts alter intrinsic excitability and synaptic excitation in the reticular thalamic nucleus. J Neurosci 30:5465-5479.
Paz JT, Davidson TJ, Frechette ES, Delord B, Parada I, Peng K, Deisseroth K, Huguenard JR (2013) Closed-loop optogenetic control of thalamus as a tool for interrupting seizures after cortical injury. Nat Neurosci 16:64-70.

Perkins LA, Hedgecock EM, Thomson JN, Culotti JG (1986) Mutant sensory cilia in the nematode Caenorhabditis elegans. Dev Biol 117:456-487.

Pomeshchik Y, Kidin I, Korhonen P, Savchenko E, Jaronen M, Lehtonen S, Wojciechowski S, Kanninen K, Koistinaho J, Malm T (2015) Interleukin33 treatment reduces secondary injury and improves functional recovery after contusion spinal cord injury. Brain Behav Immun 44:68-81.

Puñal V, Paisley C, Brecha F, Lee M, Perelli R, Wang J, O’Koren E, Ackley C, Saban D, Reese B, Kay J (2019) Large-scale death of retinal astrocytes during normal development is non-apoptotic and implemented by microglia. PLoS Biol 17:e3000492.

Purice M, Ray A, Münzel E, Pope B, Park D, Speese S, Logan M (2017) A novel Drosophila injury model reveals severed axons are cleared through a Draper/MMP-1 signaling cascade. Elife 6:e23611.

Raiders S, Black E, Bae A, Shaham S, Singhvi A (2020) Glia actively sculpt sensory neurons by controlled phagocytosis to modify animal behavior. Biorxiv. doi: https://doi.org/10.1101/2020.11.11.378893.

Ravizza T, Boer K, Redeker S, Spliet WG, van Rijen PC, Troost D, Vezzani A, Aronica E (2006) The IL-1beta system in epilepsy-associated malformations of cortical development. Neurobiol Dis 24:128-143.

Riccomagno MM, Kolodkin AL (2015) Sculpting neural circuits by axon and dendrite pruning. Annu Rev Cell Dev Biol 31:779-805.

Roche SL, Sherman DL, Dissanayake K, Soucy G, Desmazieres A, Lamont DJ, Peles E, Julien JP, Wishart TM, Ribchester RR, Brophy PJ, Gillingwater TH (2014) Loss of glial neurofascin155 delays developmental synapse elimination at the neuromuscular junction. J Neurosci 34:12904-12918.

Sapar ML, Ji H, Wang B, Poe AR, Dubey K, Ren X, Ni JQ, Han C (2018) Phosphatidylserine externalization results from and causes neurite degeneration in Drosophila. Cell Rep 24:2273-2286.

Schafer DP, Stevens B (2013) Phagocytic glial cells: sculpting synaptic circuits in the developing nervous system. Curr Opin Neurobiol 23:1034-1040.

Schafer DP, Stevens B (2015) Microglia function in central nervous system development and plasticity. Cold Spring Harb Perspect Biol 7:a020545.

Schafer DP, Lehrman EK, Kautzman AG, Koyama R, Mardinly AR, Yamasaki R, Ransohoff RM, Greenberg ME, Barres BA, Stevens B (2012) Microglia sculpt postnatal neural circuits in an activity and complementdependent manner. Neuron 74:691-705.

Schafer DP, Heller CT, Gunner G, Heller M, Gordon C, Hammond T, Wolf Y, Jung S, Stevens B (2016) Microglia contribute to circuit defects in Mecp2 null mice independent of microglia-specific loss of Mecp2 expression. Elife 5:e15224.

Scharfman HE (2007) The neurobiology of epilepsy. Curr Neurol Neurosci Rep 7:348-354.

Schluter G (1973) Ultrastructural observations on cell necrosis during formation of the neural tube in mouse embryos. Z Anat Entwicklungsgesch 141:251-264.

Scott-Hewitt N, Perrucci F, Morini R, Erreni M, Mahoney M, Witkowska A, Carey A, Faggiani E, Schuetz LT, Mason S, Tamborini M, Bizzotto M, Passoni L, Filipello F, Jahn R, Stevens B, Matteoli M (2020) Local externalization of phosphatidylserine mediates developmental synaptic pruning by microglia. EMBO J 39:e105380.

Segal M (2005) Dendritic spines and long-term plasticity. Nat Rev Neurosci 6:277-284.

Segawa K, Suzuki J, Nagata S (2011) Constitutive exposure of phosphatidylserine on viable cells. Proc Natl Acad Sci USA 108:19246-19251.

Shacham-Silverberg V, Sar Shalom H, Goldner R, Golan-Vaishenker Y, Gurwicz N, Gokhman I, Yaron A (2018) Phosphatidylserine is a marker for axonal debris engulfment but its exposure can be decoupled from degeneration. Cell Death Dis 9:1116.

Silverman SM, Wong WT (2018) Microglia in the retina: roles in development, maturity, and disease. Annu Rev Vis Sci 4:45-77.

Silverman SM, Ma W, Wang X, Zhao L, Wong WT (2019) C3- and CR3-dependent microglial clearance protects photoreceptors in retinitis pigmentosa. J Exp Med 216:1925-1943.

Singhvi A, Shaham S (2019) Glia-neuron interactions in Caenorhabditis elegans. Annu Rev Neurosci 42:149-168.

Singhvi A, Liu B, Friedman CJ, Fong J, Lu Y, Huang XY, Shaham S (2016) A glial $\mathrm{K} / \mathrm{Cl}$ transporter controls neuronal receptive ending shape by chloride inhibition of an rGC. Cell 165:936-948. 
Sipe GO, Lowery RL, Tremblay M, Kelly EA, Lamantia CE, Majewska AK (2016) Microglial P2Y12 is necessary for synaptic plasticity in mouse visual cortex. Nat Commun 7:10905.

Smith CJ, Johnson K, Welsh TG, Barresi MJ, Kucenas S (2016) Radial glia inhibit peripheral glial infiltration into the spinal cord at motor exit point transition zones. Glia 64:1138-1153.

Smith IW, Mikesh M, Lee Y, Thompson WJ (2013) Terminal Schwann cells participate in the competition underlying neuromuscular synapse elimination. J Neurosci 33:17724-17736.

Smrz D, Dráberová L, Dráber P (2007) Non-apoptotic phosphatidylserine externalization induced by engagement of glycosylphosphatidylinositolanchored proteins. J Biol Chem 282:10487-10497.

Song JW, Misgeld T, Kang H, Knecht S, Lu J, Cao Y, Cotman SL, Bishop DL, Lichtman JW (2008) Lysosomal activity associated with developmental axon pruning. J Neurosci 28:8993-9001.

Stephan AH, Barres BA, Stevens B (2012) The complement system: an unexpected role in synaptic pruning during development and disease. Annu Rev Neurosci 35:369-389.

Stevens B, Allen NJ, Vazquez LE, Howell GR, Christopherson KS, Nouri N, Micheva KD, Mehalow AK, Huberman AD, Stafford B, Sher A, Litke AM, Lambris JD, Smith SJ, John SW, Barres BA (2007) The classical complement cascade mediates CNS synapse elimination. Cell 131:1164-1178.

Takeuchi Y, Asano H, Katayama Y, Muragaki Y, Imoto K, Miyata M (2014) Large-scale somatotopic refinement via functional synapse elimination in the sensory thalamus of developing mice. J Neurosci 34:1258-1270.

Takeuchi Y, Osaki H, Yagasaki Y, Katayama Y, Miyata M (2017) Afferent fiber remodeling in the somatosensory thalamus of mice as a neural basis of somatotopic reorganization in the brain and ectopic mechanical hypersensitivity after peripheral sensory nerve injury. eNeuro 4:ENEURO.0345-16.2017.

Tasdemir-Yilmaz OE, Freeman MR (2014) Astrocytes engage unique molecular programs to engulf pruned neuronal debris from distinct subsets of neurons. Genes Dev 28:20-33.

Thanos S (1992) Sick photoreceptors attract activated microglia from the ganglion cell layer: a model to study the inflammatory cascades in rats with inherited retinal dystrophy. Brain Res 588:21-28.

Tremblay M, Lowery RL, Majewska AK (2010) Microglial interactions with synapses are modulated by visual experience. PLoS Biol 8:e1000527.

Tremblay ME, Cookson MR, Civiero L (2019) Glial phagocytic clearance in Parkinson's disease. Mol Neurodegener 14:16.

Vainchtein ID, Chin G, Cho FS, Kelley KW, Miller JG, Chien EC, Liddelow SA, Nguyen PT, Nakao-Inoue H, Dorman LC, Akil O, Joshita S, Barres BA, Paz JT, Molofsky AB, Molofsky AV (2018) Astrocyte-derived interleukin-33 promotes microglial synapse engulfment and neural circuit development. Science 359:1269-1273.

Vasek MJ, Garber C, Dorsey D, Durrant DM, Bollman B, Soung A, Yu J, Perez-Torres C, Frouin A, Wilton DK, Funk K, DeMasters BK, Jiang X, Bowen JR, Mennerick S, Robinson JK, Garbow JR, Tyler KL, Suthar MS, Schmidt RE, et al. (2016) A complement-microglial axis drives synapse loss during virus-induced memory impairment. Nature 534:538-543.

Verkhratsky A, Butt A (2013) Glial physiology and pathophysiology. Wiley Online Library. 9781118402061

Verkhratsky A, Zorec R, Rodriguez JJ, Parpura V (2016) Astroglia dynamics in ageing and Alzheimer's disease. Curr Opin Pharmacol 26:74-79.

Vezzani A, Lang B, Aronica E (2015) Immunity and inflammation in epilepsy. Cold Spring Harb Perspect Med 6:a022699.

Vilalta A, Brown GC (2018) Neurophagy, the phagocytosis of live neurons and synapses by glia, contributes to brain development and disease. FEBS J 285:3566-3575.

von Bartheld CS, Bahney J, Herculano-Houzel S (2016) The search for true numbers of neurons and glial cells in the human brain: a review of 150 years of cell counting. J Comp Neurol 524:3865-3895.
Wake H, Moorhouse AJ, Jinno S, Kohsaka S, Nabekura J (2009) Resting microglia directly monitor the functional state of synapses in vivo and determine the fate of ischemic terminals. J Neurosci 29:3974-3980.

Wallace SW, Singhvi A, Liang Y, Lu Y, Shaham S (2016) PROS-1/Prospero is a major regulator of the glia-specific secretome controlling sensory-neuron shape and function in C. elegans. Cell Rep 15:550-562.

Wan G, Corfas G, Stone JS (2013) Inner ear supporting cells: rethinking the silent majority. Semin Cell Dev Biol 24:448-459.

Wang C, Yue H, Hu Z, Shen Y, Ma J, Li J, Wang XD, Wang L, Sun B, Shi P, Wang L, Gu Y (2020) Microglia mediate forgetting via complement-dependent synaptic elimination. Science 367:688-694.

Wang X, Yang C (2016) Programmed cell death and clearance of cell corpses in Caenorhabditis elegans. Cell Mol Life Sci 73:2221-2236.

Wang Y, Cella M, Mallinson K, Ulrich JD, Young KL, Robinette ML, Gilfillan S, Krishnan GM, Sudhakar S, Zinselmeyer BH, Holtzman DM, Cirrito JR, Colonna M (2015) TREM2 lipid sensing sustains the microglial response in an Alzheimer's disease model. Cell 160:1061-1071.

Watts RJ, Schuldiner O, Perrino J, Larsen C, Luo L (2004) Glia engulf degenerating axons during developmental axon pruning. Curr Biol 14:678-684.

Weil M, Jacobson MD, Raff MC (1997) Is programmed cell death required for neural tube closure? Curr Biol 7:281-284.

Weinhard L, di Bartolomei G, Bolasco G, Machado P, Schieber NL, Neniskyte U, Exiga M, Vadisiute A, Raggioli A, Schertel A, Schwab Y, Gross CT (2018) Microglia remodel synapses by presynaptic trogocytosis and spine head filopodia induction. Nat Commun 9:1228.

Werneburg S, Jung J, Kunjamma RB, Ha SK, Luciano NJ, Willis CM, Gao G, Biscola NP, Havton LA, Crocker SJ, Popko B, Reich DS, Schafer DP (2020) Targeted complement inhibition at synapses prevents microglial synaptic engulfment and synapse loss in demyelinating disease. Immunity 52:167-182.e167.

Wilton DK, Dissing-Olesen L, Stevens B (2019) Neuron-glia signaling in synapse elimination. Annu Rev Neurosci 42:107-127.

Winfree LM, Speese SD, Logan MA (2017). Protein phosphatase 4 coordinates glial membrane recruitment and phagocytic clearance of degenerating axons in Drosophila. Cell Death Dis 8:e2623.

Wu H, Bellmunt E, Scheib J, Venegas V, Burkert C, Reichardt L, Zhou Z, Farinas I, Carter B (2009) Glial precursors clear sensory neuron corpses during development via Jedi-1, an engulfment receptor. Nat Neurosci 12:1534-1541.

Yoshida A, Nakano S, Suzuki T, Ihara K, Higashiyama T, Mori I (2016) A glial $\mathrm{K}(+) / \mathrm{Cl}(-)$ cotransporter modifies temperature-evoked dynamics in Caenorhabditis elegans sensory neurons. Genes Brain Behav 15:429-440.

Yoshida M, Satoh T, Nakamura KC, Kaneko T, Hata Y (2009) Cortical activity regulates corticothalamic synapses in dorsal lateral geniculate nucleus of rats. Neurosci Res 64:118-127.

Young RW (1967) The renewal of photoreceptor cell outer segments. J Cell Biol 33:61-72.

Young RW, Bok D (1969) Participation of the retinal pigment epithelium in the rod outer segment renewal process. J Cell Biol 42:392-403.

Zhao L, Zabel MK, Wang X, Ma W, Shah P, Fariss RN, Qian H, Parkhurst CN, Gan WB, Wong WT (2015) Microglial phagocytosis of living photoreceptors contributes to inherited retinal degeneration. EMBO Mol Med 7:1179-1197.

Zhao X, Liao Y, Morgan S, Mathur R, Feustel P, Mazurkiewicz J, Qian J, Chang J, Mathern GW, Adamo MA, Ritaccio AL, Gruenthal M, Zhu X, Huang Y (2018) Noninflammatory changes of microglia are sufficient to cause epilepsy. Cell Rep 22:2080-2093.

Zhu Y, Crowley SC, Latimer AJ, Lewis GM, Nash R, Kucenas S (2019) Migratory neural crest cells phagocytose dead cells in the developing nervous system. Cell 179:74-89.e10.

Ziegenfuss JS, Doherty J, Freeman MR (2012) Distinct molecular pathways mediate glial activation and engulfment of axonal debris after axotomy. Nat Neurosci 15:979-987. 